\title{
Inflammatory markers in the saliva of cerebral palsy individuals with gingivitis after periodontal treatment
}

\author{
Rosemeire Arai YOSHIDA ${ }^{(a)}$ \\ Renata GORJÃO(b) \\ Marcia Pinto Alves MAYER(c) \\ Paola Fernanda Leal CORAZZA(d) \\ Renata Oliveira GUARE(e) iD \\ Ana Cristina Fernandes Maria \\ FERREIRA(e) $^{(0)}$ \\ Maria Teresa Botti Rodrigues \\ SANTOS (f)

\footnotetext{
(a) Universidade Cruzeiro do Sul - Unicsul, School of Dentistry, São Paulo, SP, Brazil.

(b) Universidade Cruzeiro do Sul - Unicsul, Postgraduate Program Interdisciplinary in Health Sciences, São Paulo, SP, Brazil. of Biomedical Sciences, Department of Microbiology, São Paulo, SP, Brazil.

(d) Universidade Cruzeiro do Sul - Unicsul, School of Dentistry, Department of Periodontology, São Paulo, SP, Brazil.

(e) Universidade Cruzeiro do Sul - Unicsul, in Dentistry, São Paulo, SP, Brazil.

(f) Universidade Cruzeiro do Sul - Unicsul, Postgraduate Program in Dentistry, São Paulo, SP, Brazil.
} \\ (c) Universidade de São Paulo - USP, Institute \\ School of Dentistry, Postgraduate Program
}

Declaration of Interests: The authors certify that they have no commercial or associative interest that represents a conflict of interest in connection with the manuscript.

\section{Corresponding Author:}

Prof. Dr. Maria Teresa Botti Rodrigues Santos E-mail: drsantosmt@yahoo.com.br

https://doi.org/10.1590/1807-3107bor-2019.vol33.0033

Submitted: August 18, 2018

Accepted for publication: February 26, 2019 Last revision: March 19, 2019

\begin{abstract}
The aim of this study was to evaluate the effect of periodontal treatment on the salivary cytokine levels and clinical parameters of individuals with cerebral palsy $(\mathrm{CP})$ with gingivitis. A non-randomized, clinical trial was conducted in individuals diagnosed with spastic CP. Thirty-eight individuals were enrolled in the study and were categorized according to gingival index scores between $0-1$ or 2-3, assigned to groups G2 or G1, respectively. Periodontal treatment comprised oral hygiene instructions, conventional mechanical treatment and $0.12 \%$ chlorhexidine applied as an adjunct. Clinical parameters and saliva samples were collected at baseline and at the 15-day follow-up visit. Bleeding on probing and periodontal screening and recording were determined. Non-stimulated saliva samples were obtained, and the salivary flow rate, the osmolality and the levels of cytokines IL-1 $\beta$, IL-6, IL-8, IL-10, TNF- $\alpha$ and IL-12p70 were evaluated by a cytometric bead array. The Wilcoxon test, the Mann-Whitney test, Spearman correlation analysis, Poisson regression analysis and an adjusted analysis were performed $(\alpha=0.05)$. The groups differed significantly in periodontal clinical parameters at baseline and at follow-up. Salivary flow rate and osmolality were similar in both groups at both timepoints. However, TNF- $\alpha$ and IL-1 $\beta$ levels were higher in G1 than in G2 at baseline. Mechanical treatment resulted in improved clinical parameters for both groups. Furthermore, mechanical treatment resulted in a significant reduction in salivary IL-1 $\beta$ and IL-8 levels for both groups after treatment. Periodontal treatment performed in individuals with CP and gingivitis reduces the levels of TNF- $\alpha$, IL-1 $\beta$, IL-6 and IL-8.
\end{abstract}

Keywords: Cytokines; Biomarkers; Cerebral Palsy; Saliva.

\section{Introduction}

Gingivitis is a reversible inflammatory process, induced by the presence of microorganisms in the biofilm near the gingival margin. ${ }^{1}$ The presence of bacterial lipopolysaccharides triggers the inflammatory response of the host, activating polymorphonuclear leukocytes and the secretion of inflammatory mediators, such as cytokines and chemokines. ${ }^{2}$ Proinflammatory cytokines such as interleukin-1 beta (IL-1 $\beta$ ), tumor necrosis factor-alpha (TNF- $\alpha$ ) and interleukin-6 (IL-6) are released in response to these inflammatory and infectious stimuli. ${ }^{3}$ 
IL-1 $\beta$ is a mediator of inflammatory response, cell death by apoptosis and bone resorption. ${ }^{3}$ Among the inflammatory mediators, IL-1 $\beta$ is the one that presents the greatest correlation with the state of periodontal disease, compared with other inflammatory mediators. ${ }^{4}$ High values of TNF- $\alpha$ have been found in individuals with periodontal disease, thereby correlating this cytokine with clinical parameters indicating periodontitis. ${ }^{5}$ Elevated IL-6 levels have also been found in the crevicular gingival fluid of subjects with periodontal disease. Reduced values of both IL- 6 and IL-1 $\beta$ have been described in studies that have addressed treatments of the disease, and that have used improved clinical parameters. ${ }^{6}$

Interleukin-8 (IL-8) is an important chemokine that is associated with apical periodontitis ${ }^{7}$, and that controls the activation and migration of neutrophils the first line of defense for periodontopathogenic bacteria from peripheral blood to gingival tissues. ${ }^{8}$ Elevated levels of IL- 8 have been observed in the crevicular fluid of individuals with aggressive periodontitis. ${ }^{9}$ Interleukin-10 (IL-10) is a potent antiinflammatory cytokine that inhibits pro-inflammatory cytokines, mainly IL-1 and IL- 6 produced by activated macrophages and monocytes, and that stimulates the endogenous production of anti-inflammatory cytokines. It inhibits osteoclastic bone resorption and regulates osteoblastic bone formation. ${ }^{10}$

Saliva has been used as a study medium in individuals with cerebral palsy (CP), because it is an easily accessible fluid containing proteins, immunoglobulins and formed elements of blood from the gingival tissues. ${ }^{11}$ The changes in the inflammatory mediators present in saliva reflect the changes that occur in gingival tissue. ${ }^{12}$ Higher values of salivary osmolality have been reported in individuals with $\mathrm{CP}$ and gingivitis. ${ }^{13} \mathrm{~A}$ more pronounced gingival inflammatory status was observed in individuals with $\mathrm{CP}$ without cervical control, characterized by higher resting levels of IL-1 $\beta$, IL-6, IL-8, TNF- $\alpha$ and IgA in the saliva, compared with $\mathrm{CP}$ individuals with cervical control, who exhibited a positive relationship between the gingival index (GI) and salivary cytokines. ${ }^{12}$ Since gingivitis is a disease of high prevalence in individuals with $\mathrm{CP}$, and considering that the inflammatory markers of this process can be measured in saliva, it must be determined if the reduction in the gingival inflammatory process occurs after performing oral hygiene instruction and mechanical treatment.

Accordingly, the objectives of this study were (i) to evaluate the salivary concentrations of IL-1 $\beta$, IL-6, IL-8, IL-10, TNF- $\alpha$ and the p70 subunit of interleukin-12 (IL-12p70) in the saliva of CP individuals with gingivitis before and after periodontal treatment and application of $0.12 \%$ chlorhexidine as an adjunct; and (ii) to evaluate salivary flow and osmolality values in these same individuals before and after periodontal treatment.

The hypothesis of the study was that the proposed periodontal treatment reduces the inflammatory markers measured by the saliva of patients with CP.

\section{Methodology}

\section{Ethics statement}

This study was reviewed and approved by the Research Ethics Committee of the Cruzeiro do Sul University - Brazil Platform, São Paulo, Brazil (\# $1,938,626)$. Written informed consent was obtained from the parents or guardians of each child after they were informed about the study.

\section{Study design}

This non-randomized, parallel, 2-arm clinical trial was registered at the World Health Organization (Universal Trial Number (UTN) U1111-1200-9644) and the Brazilian Clinical Trials Registry (RBR-2YFBNP; http://www.ensaiosclinicos.gov.br/rg/RBR-2yfbnp/). This study was conducted in individuals diagnosed with spastic $\mathrm{CP}$.

\section{Sample size}

The sample calculation of this study was performed by comparing the means reported in previous studies ${ }^{12}$ that evaluated the GI of children and adolescents with cerebral palsy, including those with cervical control (GI; Mean \pm SD: $1.5 \pm 0.6$ ) and without cervical control (GI; Mean \pm SD: $0.8 \pm 0.8)^{12}$. Considering a confidence interval (CI) of $95 \%$ and a power of $80 \%$, a total of 34 individuals would be necessary, divided into 2 groups of 17 each (OpenEpi online; www.openepi.com). 


\section{Subjects}

A total of 112 individuals diagnosed with $\mathrm{CP}$, and receiving rehabilitation treatment at a referral center in São Paulo, Brazil, from May 2016 to October 2017, were invited to participate in this study.

The inclusion criteria were individuals with spastic CP, aged 6 to 14 years, of any gender. Patients with progressive or neurodegenerative lesions were excluded, as well as those who were using any drug that would interfere with salivary secretion for at least 72 hours prior to salivary collection, or who had undergone surgical procedures to control the external flow of saliva. Also excluded were those who did not collaborate with the salivary collection procedure, or who had used an antibiotic in the last month, had symptoms of fever, flu, body pains or diarrhea at the time of collection, or those with some inflammatory condition in the oral mucosa, such as aphthous ulcers.

All participants were categorized according to gingival index $(\mathrm{GI})^{14}$ scores between $0-1$ or $2-3$, assigned to groups G2 and G1, respectively. Dichotomization was used to compare the groups.

The flow diagram of this clinical study is presented in Figure.

The data related to gender, age, type of movement disorder, gross motor function classification system (GMFCS) levels I-V ${ }^{15}$, and use of medications in continuous form, were obtained from the medical records of the participants. The following evaluations were performed: (1) saliva collection to evaluate inflammatory markers in saliva, salivary flow and osmolality; and (2) evaluation of the $\mathrm{GI}^{14}$, followed by periodontal screening and recording (PSR). ${ }^{16}$ Participants in both groups underwent all assessments before and 15 days after the end of periodontal treatment. ${ }^{17}$

\section{Saliva collection}

Saliva samples for both groups were collected in the dental assessment sessions, as previously described. ${ }^{12}$ Collection of total saliva required participants not to

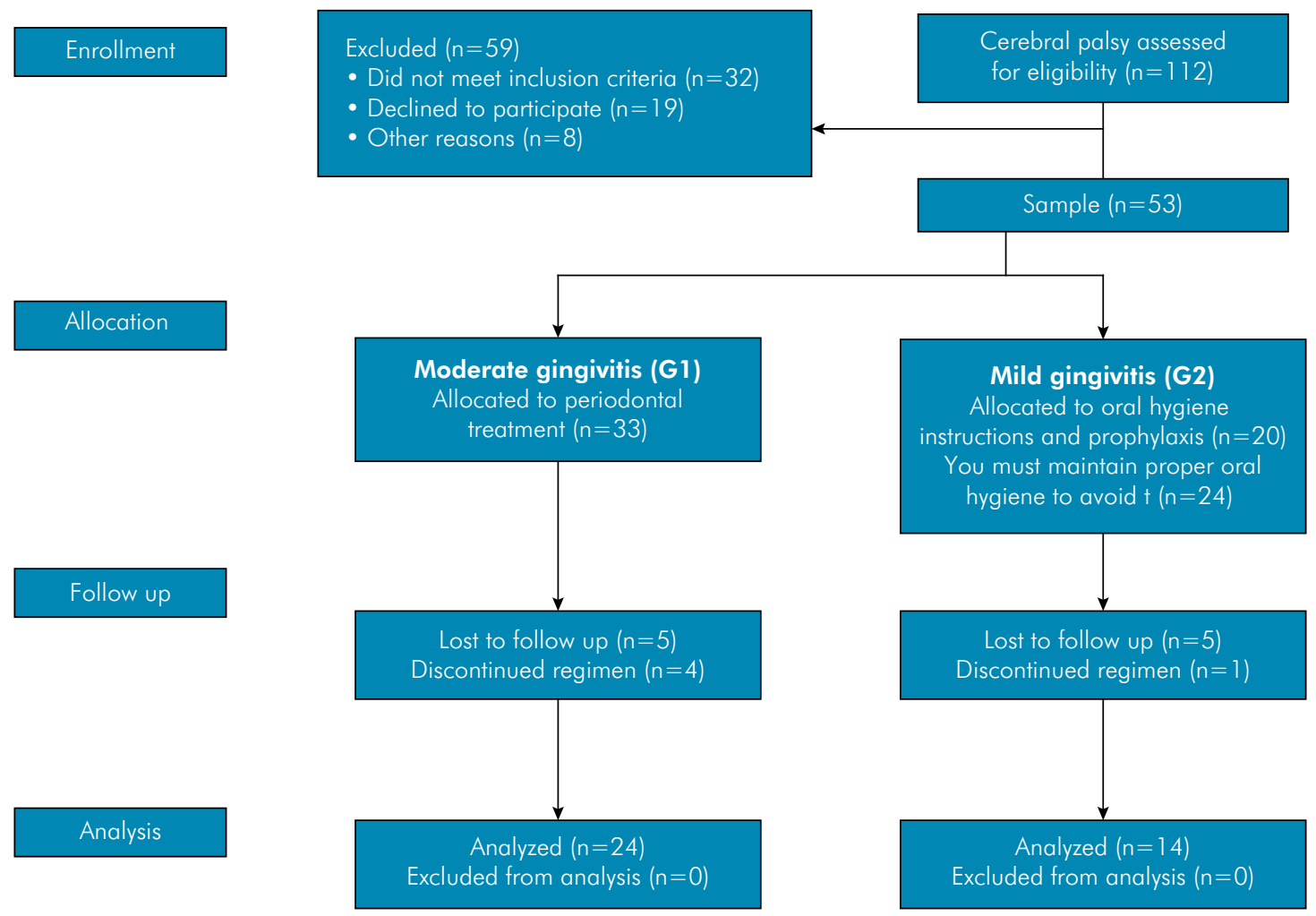

Figure. Flow diagram. 
eat or drink liquids or brush their teeth for at least 1 hour prior to collection. Total saliva was collected using an absorbent cotton roller (Salivette ${ }^{\circledR}$; Sarsted, Numbrecht, Germany $)^{18}$ positioned on the floor of the mouth for five minutes. The collection was performed with the participants sitting comfortably in a bright and well-ventilated room. After collection, the Salivette ${ }^{\circledR}$ was centrifuged at $5,000 \mathrm{rpm}$ for five minutes at $4^{\circ} \mathrm{C}$ (Hettich Centrifuge, model Universal 320R, Tuttlingen, Germany) and frozen in a freezer at $-80^{\circ} \mathrm{C}$. After the samples thawed, the volume of salivary flow was calculated by the ratio of $\mathrm{mL}$ for 5 minutes.

\section{Saliva osmolality}

Saliva osmolality was determined by observing the freezing point depression in an osmometer (Wescor Vapro® Model 5600 Vapor Pressure Osmometer; Washington, USA) as previously described. ${ }^{13}$

\section{Biomarker analysis}

The analysis of cytokines in saliva was performed using a CBA Cytokine Inflammatory Kit (Becton Dickinson, USA) to detect IL-1 $\beta$, IL-6, IL-8, IL-10, IL-12p70 and TNF- $\alpha$. All analyses were performed in duplicate.

In brief, $25 \mu \mathrm{l}$ of fluorescent particles conjugated to antibodies specific to each cytokine were added to $25 \mu \mathrm{l}$ of the saliva and incubated for one hour at room temperature, away from light. Then, $25 \mu \mathrm{l}$ of the secondary antibody conjugated to a fluorochrome was added to the mixture and incubated for two hours at room temperature. The results were compared to a standard curve with serially diluted cytokines. The particles were washed to remove the unbound antibodies, resuspended in wash buffer and analyzed using a BD Accuri (BD Biosciences). Data acquisition was performed using BD Accuri C6 Software, and concentrations were determined using FCAP Software v.3.0 (BD Biosciences).

\section{Gingival index (GI)}

The evaluation of the $\mathrm{GI}^{14}$ was performed using a plastic millimeter periodontal probe (HuFriedy's Colorvue PerioScreen Kit probe, Chicago, USA), which was gently run along the gingival margin of all teeth, in reference to the distobuccal papilla, the buccal margin, the mesiobuccal papilla and the lingual/palliative margin. Partially erupted teeth and residual roots were excluded without replacement. The index was calculated by the percentage of the sum of the individual values of each tooth divided by the number of faces examined.

Thirty-eight individuals were enrolled in the study and were categorized according to GI scores between $0-1(\mathrm{G} 2)$ or 2-3 (G1). ${ }^{14}$

\section{Periodontal Screening and Recording (PSR)}

PSR was conducted ${ }^{16}$ after evaluating the $\mathrm{GI}^{14}$. The buccal cavity was divided into sextants, and all the teeth were examined; the highest sextant score was recorded. The scores were assigned as follows: $(0)=$ colored reference mark of the millimeter probe completely visible, healthy gingival tissue, absence of bleeding and calculi; (1) = colored reference mark completely visible with bleeding upon probing; (2) $=$ colored reference mark completely visible with presence of supra- or subgingival calculi; (3) = colored reference mark partially visible, with depth upon probing between 3.5 and $5.5 \mathrm{~mm}$; and $(4)=$ colored reference mark invisible, with depth upon probing more than $5.5 \mathrm{~mm}$.

\section{Periodontal treatment}

The participants in this study were under rehabilitation treatment seeking to improve their independence. However, even individuals with GMFCS I, II and III $(n=15)$ underwent oral hygiene under the supervision of a caregiver.

The mechanical periodontal treatment sessions were performed with the participants of both groups. This consisted of oral hygiene instruction by pointing out biofilm buildup (to facilitate caregiver visualization of the places that required greater attention), followed by supervised dental brushing by the caregivers to gain skill training. Individual limitations required special contrivances, like adaptations in the brushes, construction of mouth openers with wooden spatulas, use of dental floss with handles, thickened brush handles and toothbrushes with small heads.

Root scaling and planing were performed with hand instruments after administering anesthesia 
(Gracey and McCall Curettes, Millennium - Gogra, Sao Paulo, Brazil), followed by coronal-radicular polishing. Local anesthesia was used during scraping of supragingival calculi in 19 participants in the G1 group to reduce stress, since individuals with cerebral palsy present autonomic dysfunctions with sympathetic predominance. ${ }^{19}$ Root scaling and planing were not performed in any participant in G2.

Dental prophylaxis was performed with Robson's brush and prophylactic paste (3M do Brasil, São Paulo, Brazil). In addition, participants with GI index scores between 2-3 (G1) were prescribed $0.12 \%$ chlorhexidine for 15 days, to be applied after oral hygiene with gauze. An average of 4 treatment sessions were performed, with a 7-day interval.

The participants were reassessed fifteen days after the end of the treatment ${ }^{17}$, like the initial evaluation, beginning with saliva collection, and followed by GI and PSR evaluation.

\section{Statistical analysis}

Analyses of descriptive statistics were performed to characterize the sample, calculate measures of central tendency and variability for the quantitative variables, and calculate measures of absolute and percentage frequencies for the categorical variables. The normality assumption of the quantitative variables was evaluated using the Shapiro-Wilks test. When normal distribution was observed, parametric tests were performed. Otherwise, non-parametric tests were applied to determine the significance of intragroup and intergroup differences. The chi-square test was used to analyze the variables of gender, GMFCS and drug use.

The paired t-test (parametric data) or the Wilcoxon test (non-parametric data) was used to determine significant intragroup differences in relation to the periodontal condition and salivary parameters studied before and after periodontal treatment. The independent group test (parametric data) or the Mann-Whitney test (non-parametric data) was used to identify significant intergroup differences (G1 vs. G2) in relation to the variables described above. In addition, the Spearman correlation analysis (non-parametric data) was used to assess the quantitative variables.
Finally, a Poisson regression analysis was performed to determine baseline characteristics that could explain why some children and adolescents presented higher GI values, even after periodontal treatment. Predictive variables with $\mathrm{P}<0.20$ in the univariate analysis were incorporated into the multivariate analysis. The coefficients (parameter estimates) of the regression were interpreted in terms of the incidence rate ratio (IRR), with respective 95\% CI and p-values. IBM SPSS Statistics (SPSS for Windows, Version 20.0, Armonk, USA) was used for all the analyses, set at a significance level of $5 \%$.

\section{Results}

Since the final number of G2 participants was lower $(n=14)$ than the required number $(n=17)$, the sample power was calculated using the means and standard deviations of GI between groups G1 (mean \pm SD: $1.8 \pm 0.7$ ) and G2 (mean \pm SD: $0.9 \pm 0.7$ ) (OpenEpi online; www.openepi.com). The results showed that the $G^{*}$ Power at the $95 \%$ confidence interval was $96.88 \%$.

The G1 intragroup analysis sample power was calculated using the means and standard deviation of TNF- $\alpha$ before (mean \pm SD: $7.44 \pm 3.22$ ) and after the periodontal treatment (mean \pm SD: $5.23 \pm 2.37$ ) (OpenEpi online; www.openepi.com). The results showed that the $G^{*}$ Power at the $95 \%$ confidence interval was $96.28 \%$. The G2 intragroup analysis sample power was calculated using the means and standard deviation of TNF- $\alpha$ before (mean \pm SD: $4.12 \pm 1.57$ ) and after periodontal treatment (mean \pm SD: $2.71 \pm 1.55$ ) (OpenEpi online; www.openepi. com). The results showed that the G*Power at the $95 \%$ confidence interval was $99.96 \%$.

The groups were homogenous for gender $(p=0.873)$, age $(p=0.218)$ and use of medication in continuous form $(p=0.240)$. However, groups differed significantly regarding GMFCS ( $p=0.006)$, in that G1 had a higher percentage of non-ambulatory individuals (Table 1).

Before treatment, the BOP, PSR, TNF- $\alpha$ and IL-1 $\beta$ values were significantly higher in G1 than in G2 ( $p$-values < 0.05). After treatment, the BOP, PSR, TNF- $\alpha$ and IL-1 $\beta$ values were lower than those observed 
Table 1. Distribution of individuals with $C P$ according to presence of moderate gingivitis (G1) or mild gingivitis (G2).

\begin{tabular}{|c|c|c|c|}
\hline \multirow{2}{*}{ Variable } & G1 & G2 & \multirow{2}{*}{$\mathrm{p}$-value } \\
\hline & $(n=24)$ & $(n=14)$ & \\
\hline \multicolumn{4}{|l|}{ Gender $\mathrm{n}(\%)$} \\
\hline Female & $11(45.8)$ & $6(42.9)$ & $0.873^{*}$ \\
\hline Male & $13(54.2)$ & $8(57.1)$ & \\
\hline Age in years $($ mean $\pm S D)$ & $11.8 \pm 3.5$ & $12.7 \pm 3.1$ & $0.218^{*}$ \\
\hline \multicolumn{4}{|l|}{ GMFCS§ n(\%) } \\
\hline I - II - III & $5(20.8)$ & $10(74.4)$ & \\
\hline IV - V & $19(79.2)$ & $4(28.6)$ & $0.006^{*}$ \\
\hline \multicolumn{4}{|l|}{ Use of medications $n(\%)$} \\
\hline No & $15(62.5)$ & $6(42.8)$ & $0.323^{*}$ \\
\hline Yes & $9(37.5)$ & $8(57.2)$ & \\
\hline
\end{tabular}

§GMFCS: Gross Motor Function Classification System: I: walks without limitations; II: walks with limitations; III: walks using a hand-held mobility device; IV: self-mobility with limitations; may use powered mobility; IV: transported in a manual wheelchair; *Student's t-test; ${ }^{*}$ Chi-square test. before treatment, but were also significantly higher in $G 1$ than in G2 $(p<0.05)$ (Table 2).

\section{Correlation analysis}

Statistically significant correlations were observed, as shown in Table 3. In regard to the total sample, there was a statistically significant and positive correlation between PSR and IL-6 values, both in the pretreatment evaluation (coefficient $=$ $0.470, \mathrm{p}<0.05$ ) and after the periodontal treatment (coefficient $=0.351, \mathrm{p}<0.05$ ).

In regard to the G1 data, there was a statistically significant negative correlation between PSR and TNF- $\alpha$ values both in the pretreatment evaluation (coefficient $=-0.493, \mathrm{p}<0.05$ ) and after the periodontal treatment (coefficient $=-0.426 ; p<0.05)$. In regard

Table 2. Comparative analysis of the periodontal condition, salivary flow, salivary osmolality and salivary concentrations of markers TNF $\alpha$, IL-1 $\beta$, IL-6, IL-8, IL-10 and IL-12p70, before and after periodontal treatment, considering groups G1 and G2.

\begin{tabular}{|c|c|c|c|c|c|c|}
\hline \multirow{3}{*}{ Variable } & \multicolumn{6}{|c|}{ Valuation point } \\
\hline & \multicolumn{3}{|c|}{ Before } & \multicolumn{3}{|c|}{ After } \\
\hline & Mean (SD) & Median & $I Q R$ & Mean(SD) & Median & $I Q R$ \\
\hline \multicolumn{7}{|c|}{ Group $1(n=24)$} \\
\hline $\mathrm{BOP}$ & $27.44(16.38)^{\mathrm{Aa}}$ & 24.55 & $15.23-36.73$ & $14.94(7.35)^{\mathrm{Ba}}$ & 13.60 & $11.10-18.25$ \\
\hline PSR & $1.92(0.58)^{\mathrm{Aa}}$ & 2.00 & $2.00-2.00$ & $1.38(0.82)^{\mathrm{Ba}}$ & 1.00 & $1.00-2.00$ \\
\hline Flow rate & $0.18(0.07)^{\mathrm{Aa}}$ & 0.18 & $0.13-0.23$ & $0.19(0.10)^{\mathrm{Aa}}$ & 0.16 & $0.12-0.25$ \\
\hline Osm & $138.67(19.83)^{\mathrm{Aa}}$ & 140.50 & $117.25-150.75$ & $144.93(20.42)^{\mathrm{Aa}}$ & 144.50 & $123.75-156.75$ \\
\hline $\mathrm{TNF} \alpha$ & $7.44(3.22)^{\mathrm{Aa}}$ & 8.44 & $5.40-9.27$ & $5.23(2.37)^{\mathrm{Ba}}$ & 5.30 & $3.30-6.73$ \\
\hline $12 p 70$ & $0.17(0.42)^{\mathrm{Aa}}$ & 0.00 & $0.00-0.00$ & $0.12(0.46)^{\mathrm{Aa}}$ & 0.00 & $0.00-0.00$ \\
\hline IL10 & $0.32(0.42)^{\mathrm{Aa}}$ & 0.13 & $0.00-0.57$ & $0.29(0.48)^{\mathrm{Aa}}$ & 0.00 & $0.00-0.49$ \\
\hline IL6 & $30.66(31.14)^{\mathrm{Aa}}$ & 23.44 & $2.45-56.22$ & $17.76(19.42)^{\mathrm{Aa}}$ & 12.21 & $1.74-28.61$ \\
\hline ILI $\beta$ & $296.49(202.70)^{\mathrm{Aa}}$ & 273.29 & $114.06-449.21$ & $161.66(202.63)^{\mathrm{Ba}}$ & 100.42 & $33.08-231.34$ \\
\hline IL8 & $429.21(413.99)^{\mathrm{Aa}}$ & 328.41 & $107.68-646.23$ & $269.15(322.80)^{\mathrm{Aa}}$ & 131.63 & $52.58-504.40$ \\
\hline \multicolumn{7}{|c|}{ Group $2(n=14)$} \\
\hline $\mathrm{BOP}$ & $11.61(8.00)^{\mathrm{Ab}}$ & 10.70 & $5.75-18.70$ & $7.67(5.40)^{A b}$ & 6.50 & $4.65-10.20$ \\
\hline PSR & $1.29(0.61)^{\mathrm{Ab}}$ & 1.00 & $1.00-2.00$ & $0.43(0.65)^{\mathrm{Bb}}$ & 0.00 & $0.00-1.00$ \\
\hline Flow rate & $0.20(0.09)^{\mathrm{Aa}}$ & 0.18 & $0.14-0.26$ & $0.19(0.08)^{\mathrm{Aa}}$ & 0.16 & $0.12-0.26$ \\
\hline Osm & $134.50(22.89)^{\mathrm{Aa}}$ & 137.50 & $118.50-154.25$ & $141.46(19.09)^{\mathrm{Aa}}$ & 150.00 & $134.50-158.25$ \\
\hline $\mathrm{TNF} \alpha$ & $4.12(1.57)^{\mathrm{Ab}}$ & 4.11 & $2.76-5.64$ & $2.71(1.55)^{\mathrm{Bb}}$ & 2.22 & $1.63-3.68$ \\
\hline $12 p 70$ & $0.18(0.64)^{\mathrm{Aa}}$ & 0.00 & $0.00-0.02$ & $0.00(0.00)^{\mathrm{Aa}}$ & 0.00 & $0.00-0.00$ \\
\hline IL10 & $0.54(1.02)^{\mathrm{Aa}}$ & 0.17 & $0.00-0.56$ & $0.19(0.26)^{\mathrm{Aa}}$ & 0.07 & $0.00-0.29$ \\
\hline IL6 & $20.63(32.24)^{\mathrm{Aa}}$ & 9.12 & $3.23-23.49$ & $10.42(14.26)^{\mathrm{Aa}}$ & 5.21 & $0.27-15.66$ \\
\hline $\operatorname{IL} 1 \beta$ & $166.79(163.11)^{\mathrm{Ab}}$ & 109.26 & $46.97-238.96$ & $91.54(132.18)^{\mathrm{Ab}}$ & 56.67 & $29.33-143.75$ \\
\hline IL8 & $387.65(465.69)^{\mathrm{Aa}}$ & 127.51 & $26.44-686.09$ & $177.03(185.02)^{\mathrm{Ba}}$ & 96.07 & $28.26-348.40$ \\
\hline
\end{tabular}

SD: standard deviation; IQR: interquartile range (25th-75th percentile); Osm: salivary osmolality; Bleeding on probing (BOP). Different letters denote statistically significant differences $(p<0.05)$. Uppercase letters compare values horizontally (intragroup evaluation, before treatment vs. after treatment). Lowercase letters compare values vertically (intergroup evaluation, G1 vs. G2). 
Table 3. Spearman correlation coefficients among variables of BOP, PSR, salivary flow, salivary osmolality and salivary concentrations of markers TNF $\alpha$, IL-1 $\beta$, IL-6, IL-8, IL-10 and IL-12p70.

\begin{tabular}{|c|c|c|c|c|c|c|c|c|}
\hline \multirow{2}{*}{ Variable } & \multicolumn{8}{|c|}{ Valuation point } \\
\hline & $\mathrm{BOP}$ & PSR & Flow rate & Osmolality & $\mathrm{BOP}$ & PSR & Flow rate & Osmolality \\
\hline \multicolumn{9}{|c|}{ Group $1(n=24)$} \\
\hline TNF $\alpha$ & -0.229 & $-0.493^{*}$ & 0.176 & -0.161 & -0.097 & $-0.426^{*}$ & -0.209 & 0.071 \\
\hline $12 p 70$ & -0.234 & 0.088 & -0.248 & 0.178 & -0.106 & 0.010 & $0.495^{*}$ & $-0.457^{*}$ \\
\hline IL10 & 0.129 & 0.278 & 0.112 & -0.010 & -0.113 & 0.038 & 0.029 & 0.108 \\
\hline IL6 & 0.149 & $0.485^{*}$ & -0.293 & -0.134 & 0.245 & 0.392 & -0.300 & $0.512^{*}$ \\
\hline $\operatorname{IL} 1 \beta$ & 0.121 & $0.425^{*}$ & $-0.423^{*}$ & $0.510^{*}$ & 0.110 & -0.044 & -0.364 & 0.397 \\
\hline IL8 & -0.133 & 0.306 & $-0.416^{*}$ & 0.360 & 0.065 & 0.187 & -0.357 & $0.552^{*}$ \\
\hline \multicolumn{9}{|c|}{ Group $2(n=14)$} \\
\hline TNF $\alpha$ & -0.165 & 0.298 & -0.286 & -0.160 & -0.073 & 0.065 & 0.389 & 0.187 \\
\hline $12 \mathrm{p} 70$ & -0.011 & 0.002 & 0.021 & 0.126 & 0.311 & 0.529 & -0.103 & -0.310 \\
\hline IL10 & 0.254 & 0.262 & -0.229 & 0.327 & 0.097 & -0.162 & -0.232 & 0.182 \\
\hline IL6 & 0.183 & 0.253 & -0.145 & 0.363 & -0.027 & -0.026 & 0.346 & -0.394 \\
\hline ILI $\beta$ & 0.106 & 0.293 & -0.420 & 0.398 & -0.068 & -0.169 & 0.077 & 0.134 \\
\hline IL8 & 0.055 & 0.225 & -0.524 & 0.178 & $0.603^{*}$ & 0.268 & -0.442 & 0.143 \\
\hline
\end{tabular}

Bleeding on probing (BOP). *Statistically significant correlation at $p<0.05$.

Table 4.Poisson regression analysis to determine baseline characteristics associated with higher $\mathrm{Gl}$ values after periodontal treatment.

\begin{tabular}{lcccc}
\hline \multirow{2}{*}{ Predictor variables } & \multicolumn{2}{c}{ Univariate analysis } & \multicolumn{2}{c}{ Multivariate analysis } \\
\cline { 2 - 5 } Flow rate & $0.250(0.032-1.939)$ & 0.185 & IRR $(95 \%$-valor & p-valor \\
Osmolality & $1.003(0.995-1.012)$ & 0.425 & - & 0.464 \\
TNF $\alpha$ & $1.026(0.976-1.079)$ & 0.318 & - & - \\
I2p70 & $0.907(0.595-1.384)$ & 0.652 & - & - \\
IL10 & $0.967(0.705-1.327)$ & 0.837 & - & - \\
IL6 & $1.002(0.996-1.009)$ & 0.490 & - & - \\
IL1 $\beta$ & $3.001(0.016-3.010)$ & $0.002 *$ & $3.001(0.016-3.010)$ & - \\
IL8 & $1.000(1.000-1.000)$ & 0.555 & - & - \\
\hline
\end{tabular}

IRR: incidence rate ratio; $\mathrm{Cl}$ : confidence interval; ${ }^{*} \mathrm{p}<0.05$.

to the G2 data, a statistically significant positive correlation was found only between BOP and IL-8 after periodontal treatment (coefficient $=0.603, \mathrm{p}<0.05$ ).

Table 4 shows the results of the Poisson regression analysis to determine the baseline characteristics associated with higher BOP values after periodontal treatment. In general, it was found that higher levels of IL-1 $\beta$ at baseline were associated with higher BOP values after periodontal treatment (IRR $=3.001$, $95 \% \mathrm{CI}=0.016-3.010$, univariate analysis $(\mathrm{p}=0.002)$ and multivariate analysis $(\mathrm{p}=0.006)$.

\section{Discussion}

Inflammatory markers in the saliva are important to determine the presence, risk and transition phase between healthy gingiva and gingivitis. ${ }^{20}$ This is the first study to evaluate the salivary concentrations of cytokines IL-1 $\beta$, IL-6, IL-8, IL-10, TNF- $\alpha$ and IL-12p70 in the saliva of individuals with spastic $\mathrm{CP}$ and gingivitis before and after periodontal treatment.

Saliva has been successfully employed as a means of evaluation in individuals with CP. Changes in 
salivary and biochemical parameters ${ }^{20,21,22,23}$ and in sodium and potassium ion concentration $\mathrm{s}^{21}$, reduced enzymatic antimicrobial activity, increased sialic acid concentration ${ }^{22}$, reduced salivary flow and $\mathrm{pH}$, and increased concentration and secretion of $\operatorname{sig} \mathrm{A}^{11}$ have been described in the literature as having a direct impact on the protective action of saliva. ${ }^{20}$

Inflammatory cytokines are secreted in response to inflammatory and infectious stimuli, with higher concentrations of these cytokines in the saliva of individuals with periodontal disease. ${ }^{4}$ Comparisons between the individuals in G1 and G2 in this study demonstrated that there was a reduction in the salivary concentrations of TNF- $\alpha$, IL-1 $\beta$, IL-6, IL-8, IL-10 and IL-12p70 after periodontal treatment. However, not all reductions were statistically significant. Significantly higher values were found even after periodontal treatment in G1 for TNF- $\alpha$ and IL-1 $\beta$. The periodontal treatment comprised $0.12 \%$ chlorhexidine applied as an adjunct after oral hygiene with gauze. It is important to highlight that $\mathrm{CP}$ individuals cannot maintain an adequate level of plaque control using mechanical cleaning methods alone, therefore, $0.12 \%$ chlorhexidine is used to help improve the results.

High levels of IL-1 $\beta$ are related to the pathogenesis and progression of periodontal disease, because the secretion of this cytokine requires the exposure of cellular alterations or stress signals triggering the activation of inflammatory cells, which mediate the action of caspase-1, essential for IL-1 $\beta$ activation. ${ }^{24}$

In general, IL-1 $\beta$ plays an important role in the neutrophil migration capacity by stimulating the spread of these cells through the blood vessels. Reducing the concentration of this cytokine may decrease the need for migration, since the inflammatory process is reduced. By mechanically removing the biofilm, as part of the periodontal treatment, the challenge was lower, and the synthesis of these cytokines was also reduced. Although IL-1 $\beta$ values decreased in both groups (G1: 45.5\%, G2: 45.3\%), the final levels were high compared with previous studies on healthy $(25.3 \pm 38.9 \mathrm{pg} / \mathrm{mL})$ or gingivitis subjects $(30.3 \pm 39.1){ }^{20}$ The higher levels of IL-1 $\beta$ observed in this study were also identified in individuals with $\mathrm{CP}$ without cervical control. ${ }^{12}$
Similar levels of IL-8 secretion were observed prior to treatment for both groups. However, after treatment, G2 presented a greater reduction (34.5\%) than G1. The expression of this chemokine indicates the presence of an inflammatory process, signaling the progression of periodontal disease., ${ }^{9,25}$ This chemokine promotes the recruitment of immune cells to tissue, especially neutrophils. ${ }^{26}$ In the case of neutrophils, chemotaxis allows the cell to reach the infected or injured area to effect phagocytosis and destruction of microorganisms by producing reactive oxygen species and proteolytic enzymes. ${ }^{27}$ Thus, the reduction of IL-8 expression in saliva may be indicative of a reduction in the recruitment of these cells, and a consequent resolution of the inflammatory process, as observed in G2.

A reduced salivary flow rate is considered an important risk factor for gingival disease. ${ }^{13}$ In this study, a negative and significant correlation between salivary flow and IL- 8 was observed in the total sample both before and after periodontal treatment, confirming the importance of salivary flow in the inflammatory gingival process.

The TNF- $\alpha$ proinflammatory cytokine dropped by $34.2 \%$ in G2 and $29.7 \%$ in G1 after treatment. Individuals with high salivary values of this cytokine showed significantly more bleeding sites on probing., ${ }^{5,28}$ There is a strong association between TNF- $\alpha$ and the pathophysiology of periodontitis, meaning that this marker could serve as an auxiliary method for diagnosing and treating periodontal disease. ${ }^{5,28}$

Individuals with $\mathrm{CP}$ display changes in the balance of the autonomic nervous system, with sympathetic predominance, and long-term health conditions. ${ }^{19}$ This adrenergic predominance contributes to reducing salivary flow, and increasing both salivary osmolality ${ }^{29}$ and the risk of periodontal disease. ${ }^{12,13}$ In this study, the reduced flow values and the high values of salivary osmolality did not differ between G1 and G2, because both presented gingivitis.

Another important correlation found in this study was between PSR and IL-6, which confirmed the presence of periodontal disease ${ }^{6}$ in the total sample before and after treatment (data not shown).

Further research is required to evaluate the effects of reduced salivary flow rate, increased 
salivary osmolality, antiepileptic drug use, mouth breathing and disturbed sympathovagal balance on the resistance of $\mathrm{CP}$ individuals to conventional gingivitis treatment.

In a study carried out by our group, the gingival health of 1,259 children and adolescents with physical disabilities was evaluated in a physical rehabilitation program at a reference center in São Paulo, Brazil. ${ }^{30}$ The CP group consisted of $869(69.1 \%)$ participants, and the other group comprised 390 (30.9\%) participants with diagnoses of neuromuscular disease, acquired childhood brain injury, congenital malformation, spinal cord injury, and myelomeningocele. The groups differed significantly regarding the presence of gingival inflammation $(\mathrm{p}<0.001)$. The group with CP presented only $25.2 \%(n=219)$ of participants with good gingival health, while 74.8\% $(n=650)$ had gingival inflammation, of which $54.7 \%(n=397)$ had moderate inflammation. In the group with other deficiencies, $44.1 \%(n=172)$ of the participants had good gingival health. In view of these results, it is necessary to think about a possible alteration in the inflammatory response in individuals with CP.

When performing the periodontal examination of an individual with $\mathrm{CP}$ and deciding whether to administer periodontal therapy, it is important to identify whether a certain inflammatory marker is elevated. Regression analysis showed an association between baseline levels of IL-1 $\beta$ and the response to periodontal treatment. Individuals with $\mathrm{CP}$ who present higher levels of this interleukin have greater susceptibility to periodontal disease, and, consequently, greater resistance to treatment. Accordingly, despite the treatment given, a group of children and adolescents in this study was found to be refractory to mechanical treatment, thus making it difficult to achieve good gingival health in most cases of G1.

The limitations of this study were the use of a convenience sample and the loss of participants to follow-up, due to issues related to hospitalizations, health problems, orthopedic surgeries, transportation difficulties and dependence on the availability of caregivers to accompany children and adolescents for at least six sessions to finalize the data collection. However, despite the loss of participants in the G2 group, the calculated $\mathrm{G}^{*}$ Power was $96.88 \%$. Thus, the discontinuation by 3 participants in the G2 group did not impact the results obtained.

\section{Conclusion}

Periodontal treatment performed in individuals with $\mathrm{CP}$ and gingivitis reduces the levels of TNF- $\alpha$, IL-1 $\beta$, IL-6 and IL-8.

\section{Acknowledgements}

This study was supported by the São Paulo Research Foundation (Fundação de Amparo à Pesquisa do Estado de São Paulo, FAPESP \#2014/15662-1) and National Council for Scientific and Technological Development (Conselho Nacional de Desenvolvimento Científico e Tecnológico, CNPq \#800183/2016-8).

\section{References}

1. Madianos PN, Bobetsis YA, Kinane DF. Generation of inflammatory stimuli: how bacteria set up inflammatory responses in the gingiva. J Clin Periodontol. 2005;32(6 Suppl 6):57-71. https://doi.org/10.1111/i.1600-051X.2005.00821.x

2. Yucel-Lindberg T, Båge T. Inflammatory mediators in the pathogenesis of periodontitis. Expert Rev Mol Med. 2013 Aug;15:e7. https://doi.org/10.1017/erm.2013.8

3. Zhu H, Lin X, Zheng P, Chen H. Inflammatory cytokine levels in patients with periodontitis and/or coronary heart disease. Int J Clin Exp Pathol. 2015 Feb;8(2):2214-20.

4. Gomes Fl, Aragão MG, Barbosa FC, Bezerra MM, de Paulo Teixeira Pinto V, Chaves HV. Inflammatory cytokines Interleukin-1 $\beta$ and tumour necrosis factor- $\alpha$ - novel biomarkers for the detection of periodontal diseases: a literature review. J Oral Maxillofac Res. 2016;7(2):e2. https://doi.org/10.5037/jomr.2016.7202

5. Frodge BD, Ebersole JL, Kryscio RJ, Thomas MV, Miller CS. Bone remodeling biomarkers of periodontal disease in saliva. J Periodontol. 2008 Oct;79(10):1913-9. https://doi.org/10.1902/jop.2008.080070 
- Inflammatory markers in the saliva of cerebral palsy individuals with gingivitis after periodontal treatment

6. Kardeşler L, Buduneli N, Çetinkalp S, Lappin D, Kinane DF. Gingival crevicular fluid IL-6, +PA, PAI-2, albumin levels following initial periodontal treatment in chronic periodontitis patients with or without type 2 diabetes. Inflamm Res. 2011 Feb;60(2):143-51. https://doi.org/10.1007/s00011-010-0248-7

7. Marton IJ, Rot A, Schwarzinger E, Szakáll S, Radics T, Vályi-Nagy I, et al. Differential in situ distribution of interleukin-8, monocyte chemoattractant protein-1 and Rantes in human chronic periapical granuloma. Oral Microbiol Immunol. 2000 Feb;15(1):63-5. https://doi.org/10.1034/j.1399-302x.2000.150111.x

8. Zhang $\mathrm{N}, \mathrm{Xu}$ Y, Zhang B, Zhang T, Yang H, Zhang B, et al. Analysis of interleukin-8 gene variants reveals their relative importance as genetic susceptibility factors for chronic periodontitis in the Han population. PLoS One. 2014 Aug;9(8):e104436. https://doi.org/10.1371/journal.pone.0104436

9. Ertugrul AS, Sahin H, Dikilitas A, Alpaslan N, Bozoglan A. Comparison of CCL28, interleukin-8, interleukin-1 $\beta$ and tumor necrosis factor-alpha in subjects with gingivitis, chronic periodontitis and generalized aggressive periodontitis. J Periodontal Res. 2013 Feb;48(1):44-51. https://doi.org/10.1111/j.1600-0765.2012.01500.x

10. Zhang $Q$, Chen B, Yan F, Guo J, Zhu X, Ma S, et al. Interleukin-10 inhibits bone resorption: a potential therapeutic strategy in periodontitis and other bone loss diseases. BioMed Res Int. 2014;2014:284836. https://doi.org/10.1155/2014/284836

11. Leite MF, Aznar LC, Ferreira MC, Guaré RO, Santos MT. Increased salivary immunoglobulin A and reduced $\alpha$-amylase activity in whole saliva from spastic cerebral palsy individuals. J Oral Pathol Med. 2013 Jul;42(6):480-5. https://doi.org/10.1111/jop.12047

12. Santos MT, Diniz MB, Guaré RO, Ferreira MC, Gutierrez GM, Gorião R. Inflammatory markers in saliva as indicators of gingival inflammation in cerebral palsy children with and without cervical motor control. Int J Paediatr Dent. 2017 Sep;27(5):364-71. https://doi.org/10.1111/ipd.12270

13. Santos MT, Ferreira MC, Guaré RO, Diniz MB, Rösing CK, Rodrigues JA, et al. Gingivitis and salivary osmolality in children with cerebral palsy. Int J Paediatr Dent. 2016 Nov;26(6):463-70. https://doi.org/10.1111/ipd.12220

14. Löe H. The Gingival Index, the Plaque Index and the Retention Index Systems. J Periodontol. 1967 Nov-Dec;38(6 Suppl):610-6. https://doi.org/10.1902/jop.1967.38.6.610

15. Palisano RJ, Rosenbaum P, Bartlett D, Livingston MH. Content validity of the expanded and revised Gross Motor Function Classification System. Dev Med Child Neurol. 2008 Oct;50(10):744-50. https://doi.org/10.1111/i.1469-8749.2008.03089.x

16. Lo Frisco C, Cutler R, Bramson JB. Periodontal screening and recording: perceptions and effects on practice. J Am Dent Assoc. 1993 Jul;124(7):226-9. https://doi.org/10.14219/jada.archive.1993.0256

17. Rotteveel LJ, Jongerius PH, van Limbeek J, Hoogen FJ. Salivation in healthy schoolchildren. Int J Pediatr Otorhinolaryngol. 2004 Jun;68(6):767-74. https://doi.org/10.1016/i.ijporl.2004.01.005

18. Sexton WM, Lin Y, Kryscio RJ, Dawson DR 3rd, Ebersole JL, Miller CS. Salivary biomarkers of periodontal disease in response to treatment. J Clin Periodontol. 2011 May;38(5):434-41. https://doi.org/10.1111/j.1600-051X.2011.01706.x

19. Siqueira WL, Santos MTR, Oliveira E, Nicolau J. Comparison of electrolyte concentrations in whole saliva of individuals with and without cerebral palsy. Quintessence Int. 2007 Apr;38(4):301-6.

20. Syndergaard B, Al-Sabbagh M, Kryscio RJ, Xi J, Ding X, Ebersole JL, et al. Salivary biomarkers associated with gingivitis and response to therapy. J Periodontol. 2014 Aug;85(8):e295-303. https://doi.org/10.1902/jop.2014.130696

21. Santos MT, Guaré R, Leite M, Ferreira MC, Nicolau J. Does the neuromotor abnormality type affect the salivary parameters in individuals with cerebral palsy? J Oral Pathol Med. 2010 Nov;39(10):770-4. https://doi.org/10.1111/j.1600-0714.2010.00919.x

22. Santos MT, Batista R, Guaré RO, Leite MF, Ferreira MC, Durão MS, et al. Salivary osmolality and hydration status in children with cerebral palsy. J Oral Pathol Med. 2011 Aug;40(7):582-6. https://doi.org/10.1111/i.1600-0714.2011.01027.x

23. Preshaw PM, Taylor JJ. How has research into cytokine interactions and their role in driving immune responses impacted our understanding of periodontitis? J Clin Periodontol. 2011 Mar;38 Suppl 11:60-84. https://doi.org/10.1111/j.1600-051X.2010.01671.x

24. Finoti LS, Nepomuceno R, Pigossi SC, Corbi SC, Secolin R, Scarel-Caminaga RM. Association between interleukin- 8 levels and chronic periodontal disease: A PRISMA-compliant systematic review and meta-analysis. Medicine (Baltimore). 2017 Jun;96(22):e6932. https://doi.org/10.1097/MD.0000000000006932

25. Gamonal J, Acevedo A, Bascones A, Jorge O, Silva A. Characterization of cellular infiltrate, detection of chemokine receptor CCR5 and interleukin-8 and RANTES chemokines in adult periodontitis. J Periodontal Res. 2001 Jun;36(3):194-203. https://doi.org/10.1034/j.1600-0765.2001.360309.x

26. Cooper PR, Palmer LJ, Chapple IL. Neutrophil extracellular traps as a new paradigm in innate immunity: friend or foe? Periodontol 2000. 2013 Oct;63(1):165-97. https://doi.org/10.1111/prd.12025

27. Noh MK, Jung M, Kim SH, Lee SR, Park KH, Kim DH, et al. Assessment of IL-6, IL- 8 and TNF- $\alpha$ levels in the gingival tissue of patients with periodontitis. Exp Ther Med. 2013 Sep;6(3):847-51. https://doi.org/10.3892/etm.2013.1222

28. Ferreira MC, Pastore C, Imada R, Guaré R, Leite M, Poyares D, et al. Autonomic nervous system in individuals with cerebral palsy: a controlled study. J Oral Pathol Med. 2011 Aug;40(7):576-81. https://doi.org/10.1111/j.1600-0714.2011.01008.x 
Yoshida RA, Gorjão R, Mayer MPA, Corazza PFL, Guare RO, Ferreira ACFM et al.

29. Santos MT, Guaré RO, Leite MF, Ferreira MC, Durão MS, Jardim JR. Salivary osmolality in individuals with cerebral palsy. Arch Oral Biol. 2010 Nov; 55(11):855-60. https://doi.org/10.1016/i.archoralbio.2010.07.016

30. Santos MT, Ikeda AP, Santos RC, Rodrigues MR, Gutierrez GM, Diniz MB, et al. Saúde bucal de 1.259 crianças e adolescentes com deficiência física no município de São Paulo. Braz Oral Res. 2017;31(2 Suppl):54. 